\title{
Diurnal and flavor effects on antinociception in infant rats
}

\author{
KENNETH F. GREEN, RACHEL J. BEITNER, CAROLYN E. SCHLUNDT, and SUSAN O. WERNER \\ Califomia State University, Long Beach, Califormia
}

\begin{abstract}
We examined whether infant rats would display a diurnal variation in antinociception that was produced by oral infusion of nutritive and nonnutritive fluids. Ten-day-old pups were assigned to one of four fluid conditions (milk, sucrose, saccharin, and water) or one of three conditions that controlled for the stress of the infusion procedure, either during the dark or during the light. Longer paw lift latencies were observed under dark than under light conditions in all control conditions and in most fluid-infusion conditions, indicating that antinociception is influenced by diurnal variables in the 10-day-old rat. Saccharin, milk, and water were effective in elevating paw lift latencies, but sucrose was not, indicating that the nutritive value of fluids is less important than flavor in producing antinociception. The antinociceptive effects of the diurnal cycle and the infused fluids appeared to be additive.
\end{abstract}

Infant rats display antinociception immediately after brief oral exposures to liquids such as sucrose solution (Blass, Fitzgerald, \& Kehoe, 1987), milk (Blass \& Fitzgerald, 1988), saccharin or salt (Kehoe \& Sakurai, 1991), or corn oil (Shide \& Blass, 1989). Antinociceptive responding varies with the different fluids. For example, in comparisons of nutritive fluids, milk has been found to have stronger effects than sucrose (e.g., Blass, 1992), and in comparisons of nonnutritive fluids, saccharin has been found to yield greater antinociception than salt (Kehoe \& Sakurai, 1991). Direct comparisons of nutritive with nonnutritive solutions appear to be needed. Thus one purpose of the present work was to compare the effects of saccharin and two examples of nutritive solutions, sucrose and milk, on nociceptive sensitivity in infant rats.

Also of interest was the effect of the diurnal cycle on nociceptive sensitivity in infant rats. It has been reported that adult rats and mice show a marked daily variation in nociceptive thresholds, with lowest thresholds in the early light phase and highest thresholds in the late dark phase (Akunne \& Soliman, 1987; Bar-Or \& Brown, 1989; Fredrickson, Burgis, \& Edwards, 1977; Kavaliers \& Hirst, 1983; Wirz-Justice, 1987). The thresholds can be reduced by naloxone and elevated by morphine. Diurnal rhythms in several behavioral and physiological systems have been described in young rats, including activity (G. K. Smith \& Anderson, 1977), suckling and feeding (Levin \& Stern, 1975), locomotion (Honma, Honma, Shirakawa, \& Hiroshige, 1987 ), temperature (Nusselein \& Schmidt, 1990), adreno-corticosterone (Takahashi, Hayafuji, \& Murakami, 1982), serotonin $N$-acetyltransferase (Sugishita et al., 1993), and opioid control of luteinizing hor-

Address correspondence to K. F. Green, Psychology Department, California State University, Long Beach, 1250 Bellflower Boulevard, Long Beach, CA 90840-0901 (e-mail: kgreen@csulb.edu). mone release (Jacobson \& Wilkinson, 1985). Thus a second purpose of the present work was to compare nociceptive responses in 10-day-old rats in the early light phase to those in the dark phase in order to determine whether antinociception in pups varies in a circadian fashion.

In the experiment to follow, infant rats were tested at two times of day, once during the early light phase of the diurnal cycle, and once during the dark phase. All pups were weighed, voided, and marked for identification prior to other manipulations. Within each phase, four separate sets of pups were given brief oral infusions of nutritive fluids (milk and sucrose), which have been reported to yield strong antinociception (Blass \& Fitzgerald, 1988; Blass et al., 1987), and nonnutritive fluids (saccharin, distilled water), with saccharin intended to activate opioid antinociception (Kehoe \& Sakurai, 1991) and distilled water intended as a control for infusion of fluid into the mouth. As shall be seen, antinociceptive responding to water was strong enough to justify treating it as a flavor. An additional three groups of pups were included as controls to evaluate different degrees of stress associated with experimental procedures: one group of pups was given all experimental procedures except infusion (cannula only); one group was given all experimental treatments except cannulation and infusion (no cannula); and a final group was weighed, voided, and marked, and then kept with the dam in the home cage until time of testing (dam control).

\section{METHOD}

\section{Participants}

Data are reported from 342 10-day-old rats of both sexes from 56 litters. The number of pups per litter actually completing the experiment ranged from 2 to 12 . The pups were bred from Wistar stock which was originally purchased from Simonsen Laboratories of Gilroy, CA. Breeders were housed individually in plastic cages with wood chip bedding. Breeders were handled and weighed 
twice a week. Mating entailed placing a pair of females with a male for 5-7 days, after which they were returned to individual housing. Pregnant females were observed daily at 0800 for births. The first day a litter was observed was designated Day 0 . On Day 1 , litters with more than 12 pups were culled to 12 . All pups in a litter were run on Day 10 and were required to weigh between 18 and $28 \mathrm{~g}$. No more than 2 pups per litter were assigned to any one condition. Females were allowed at least 10 days without pups before being mated again. Two lighting schedules were used, each of which was in effect at least 1 month prior to mating: 233 pups were run when the lighting in the colony followed a schedule of $12 \mathrm{~h}$ on and $12 \mathrm{~h}$ off, with lights on at 0600 ; for logistic reasons, a new lighting schedule of $15 \mathrm{~h}$ on and $9 \mathrm{~h}$ off, with lights on at 1800 , was instituted for the final 109 pups.

\section{Procedure}

The procedures were patterned after those described by Blass and Fitzgerald (1988) and Phifer and Hall (1987). Before handling the pups, all the experimenters made an effort to warm their hands to $33^{\circ} \mathrm{C}$. The pups were taken individually or in pairs from the home cage, marked on the back with ink for identification, and weighed in an 8-oz plastic cereal cup lined with wood chip bedding. After weighing, an effort was made to stimulate the pups to void urine and feces by brushing gently in the anogenital region with a No. 5 camel's hair brush that had been moistened in a $33^{\circ} \mathrm{C}$ water bath. Brushing continued for at least $30 \mathrm{sec}$ or until voiding stopped. The pup was then weighed again and was either re-placed with the mother (dam control) or placed with other pups in a 16oz plastic cereal cup which was on a heating pad set to $33^{\circ} \mathrm{C}$, was lined with wood chip bedding, and was covered by a strip of black Masonite to retain heat.

As soon as the last pup was voided, oral cannulation began. Oral cannulation was done under the lowest intensity setting of a Dolan-Jenner Series 180 illuminator and required 15-20 sec. Cannulas were made from 9-cm lengths of PE-10 tubing, heat-flared at one end to prevent them from pulling through the mouth. Each cannula was press fit onto a $5-\mathrm{cm}$ length of 26-gauge stainless steel wire, which was sharpened at one end and bent into a hook. For cannulation, each pup was gently held in a supine position, allowing access to the mouth. The sharpened end of the wire was inserted into the pup's mouth, directed below the tongue, and pushed through the soft tissue between the mandibles, enabling the cannula to exit near the submental vibrissa. Only pups that showed no signs of oral bleeding at this time (and at any other time during the experiment) were kept in the experiment.

Immediately after cannulation, the pups were placed in pairs or triples in any five of six 8-oz cups lined with wood chips that were located in a Precision Model 183 water bath. No more than 3 pups were grouped together because of limitations in the infusion and testing: we could infuse and test only 2 pups at a time; we reasoned that if larger groups were used, pups tested later would experience increasing stress as pups tested earlier were removed from the group. The temperature was kept at $33^{\circ} \mathrm{C}$, and was monitored by a thermometer. The cups in the bath were covered with a piece of clear plastic to encourage retention of heat and to prevent escape. During dark conditions, a piece of black construction paper was used in addition to the plastic plate. The pups remained in pairs or triples for 45-90 min prior to administration of the experimental procedures.

Formal experimentation began with the placing of the pups in individual 8-oz cups that were lined with wood chip bedding and were kept covered in the warm water bath. When pups were taken from a pair, each member of the pair was placed in a separate container for experimentation; when a pup was taken from a triple, the 1 st pup was isolated for experimentation and the pair that remained was kept together until it was their time for isolation and testing. After 10-15 min, the pups in the infusion groups had a length of PE-50 tubing pressure fit over the free end of their can- nulas. The PE-50 tubing was attached to a syringe mounted in a Harvard Apparatus Model 22 pump set to deliver fluid at a rate of $0.06 \mathrm{ml} / \mathrm{min}$ for $3 \mathrm{~min} 20 \mathrm{sec}$. The groups were designated by the fluid that was infused. The water group was given Arrowhead distilled water; the saccharin group was given $0.15 \%$ (wt/vol) saccharin dissolved in Arrowhead distilled water; the milk group was given undiluted half and half; and the sucrose group was given $9 \%(\mathrm{wt} / \mathrm{vol})$ sucrose dissolved in Arrowhead distilled water. All fluids, syringes, and PE-50 tubing were heated to $33^{\circ} \mathrm{C}$ prior to placement on the pump. Normally there was little reaction to fluid infusion other than treading with the front paws and movements of the mouth. Pups showing adverse reactions to infusion, such as vocalizing, struggling, rolling, and so forth, were eliminated from the study.

The testing of the infused animals began within $0-2$ min of the completion of infusion, depending on whether the pup was the 1 st or 2 nd of the infused pair to be tested and, in the case of the 2 nd pup, on the latency of the 1 st pup. The testing of control animals occurred during the time when the experimental animals were being infused. Each pup was held firmly but gently in the experimenter's right hand so that the body, three legs, and head were supported and the left front forepaw extended downward. Two paw lift tests were given. The first test, a control paw lift test, was intended to control for general activity and entailed placing the forepaw on the $33^{\circ} \mathrm{C}$ heating pad until the pup lifted it or until a cutoff latency of $15 \mathrm{sec}$ was reached, whichever occurred sooner. The test for nociception followed immediately, with the forepaw placed on a $48.5^{\circ} \mathrm{C}$ surface until the pup lifted it or until a cutoff latency of $90 \mathrm{sec}$ was reached. On completion of the second pawlift test, the pups were group housed in 16-oz cups, lined with wood chip bedding, in an incubator heated to $33^{\circ} \mathrm{C}$, with the door closed for sound insulation.

These procedures were carried out at two time periods during the diurnal cycle. The light conditions were conducted with normal fluorescent lighting. The procedures began $30 \mathrm{~min}$ after the colony lights came on, thus placing the time of nociceptive testing between 1.5 and $2.5 \mathrm{~h}$ into the light portion of the diurnal cycle. The dark conditions were conducted under indirect illumination from two shrouded desk lamps, one with a $40-\mathrm{W}$ bulb and the other with a $25-\mathrm{W}$ bulb, both located more than $1.5 \mathrm{~m}$ from the warm water bath. Additional illumination was used sparingly, as follows: a flashlight was used to locate pups in the colony and during voiding; and during cannulation, a fiber optic illuminator was used as described above. No attempt was made to cover the lights with red material. Procedures began at either of two time periods during the dark phase, either $30 \mathrm{~min}$ after the lights went off under the 12:12-h schedule, placing nociceptive testing at $1.5-2.5 \mathrm{~h}$ into the dark portion of the cycle, or $4 \mathrm{~h}$ after the lights went off under the 15:9-h schedule, placing nociceptive testing at 5.5-6.5 h into the dark portion of the cycle.

\section{Data Treatment}

Table 1 summarizes the 14 groups formed by factorial combination of two stages in the diurnal cycle (light vs. dark) and seven procedural conditions (control groups for three levels of procedural stress plus four experimental groups defined by infusion of water, saccharin, milk, and sugar). The table gives the numbers of participants in each group before and after identification and elimination of outliers. To identify outliers, a frequency distribution of paw lift latencies during the nociception test trial was constructed for each of the 14 groups, and any pup whose score deviated from the mean by more than two standard deviations was excluded. Analysis of variance was used, with two betweengroups factors, and the following planned comparisons were performed: (1) between light and dark groups within each condition, in order to assess the antinociceptive effects of the diurnal cycle (for the three control groups, longer latencies were expected during the dark, so that one-tailed tests were appropriate; for the four 
Table 1

Design of Experiment and Numbers of Pups in Each Group Before and $A$ ffer Identification of Outliers

\begin{tabular}{lccccc}
\hline & \multicolumn{3}{c}{ Time of Day } \\
\cline { 2 - 3 } \cline { 5 - 6 } Condition & Before & After & & \multicolumn{2}{c}{ Dark } \\
\cline { 2 - 5 } \cline { 5 - 6 } Dam control & 32 & 30 & & After \\
No cannula & 28 & 27 & & 22 & 26 \\
Cannula only & 27 & 25 & & 21 & 20 \\
Water & 27 & 26 & & 20 & 19 \\
Saccharin & 27 & 27 & & 20 & 20 \\
Milk & 16 & 15 & 12 & 12 \\
Sucrose & 10 & 9 & 8 & 8 \\
\hline
\end{tabular}

Note-The second and fourth columns give the number of pups after outliers were removed.

fluid-infused groups, no directional prediction was made, so twotailed tests were performed); (2) between each infused group and the cannula-only group within a given time of day, in order to assess whether fluids increased antinociception; (3) among combined light and dark groups infused with each fluid, in order to determine whether the different types of fluid produced different antinociceptive effects; and (4) between each control group combined across time of day, in order to assess whether antinociception was increased by increasing degrees of procedural stress.

\section{RESULTS}

Control paw lifts were evaluated in two ways: first by examining the percentage of pups that reached the cutoff latency of $15 \mathrm{sec}$, and second by examining the mean latencies of each group. Overall, $15 \%$ of the pups performed a paw lift prior to the cutoff latency, with no difference between light and dark. Notably, $53 \%$ of the dam control-light group failed to meet criterion; no other group exceeded $26 \%$ at either time of day. As can be seen in Figure 1, the mean latencies of each group were consistent with the percentage data. The dam control-light group was lower than all other groups and accounted for both a time of day $\times$ condition interaction $[F(6,271)=$ $2.96, p<.01]$ and a main effect of condition $[F(6,271)=$ $6.170, p<.01]$.

Test paw lift latencies are shown in Figure 2. In the control groups, latencies tended to increase with degree of stress from shortest in the dam controls to longest in the cannula-only controls. Latencies were also longer in the dark than in the light. A simple effects analysis of variance was performed on the control groups in order to evaluate paw lift latencies as a function of increasing levels of procedural stress. Time of day $[F(1,144)=65.382$, $p<.01]$, condition $[F(2,144)=21.054, p<.01]$, and the interaction $[F(2,144)=4.154, p<.02]$ were all significant, reflecting a tendency for dark conditions to enhance the increase in latencies in the groups experiencing greater procedural stress. Comparisons between light and dark groups within each condition indicated that latencies during the dark were significantly higher than those during the light (beyond the .05 level in the dam control group and beyond the .01 level in the other two groups). Comparisons among control conditions com- bined across time of day indicated that the cannula-only controls had longer latencies than did the dam controls $(p<.01)$; the no-cannula controls did not differ from the other groups. Because the procedures clearly elicited some antinociception, the cannula-only groups were chosen as the proper controls to use for evaluating the effects of fluid infusion at each time of day.

Relative to the appropriate cannula-only control groups, fluid infusions produced marked elevations in paw lift latencies during the dark in the water, saccharin, and milk groups. During the light, however, latencies were only slightly elevated, with the greatest increase occurring in the saccharin group. Sucrose infusion appeared not to affect paw lift latencies at either time of day. Analysis of variance supported these observations, with significant main effects of time of day $[F(1,272)=101.43, p<.01]$ and condition $[F(6,272)=22.813, p<.01]$. The enhanced effects of water, saccharin, and milk during the dark accounted for a significant interaction $[F(6,272)=3.662$, $p<.01]$. Except for the sucrose group, which showed no effect of time of day, comparisons indicated that latencies during the dark were significantly higher than those during the light (beyond the .01 level in all groups). Comparisons between groups infused with fluids and the appropriate cannula-only controls were performed for each time of day. During the light, only the saccharin group showed greater paw lift latencies than the lightcannula-only control $(p=.011)$, whereas during the dark, both the water and saccharin groups had longer la-

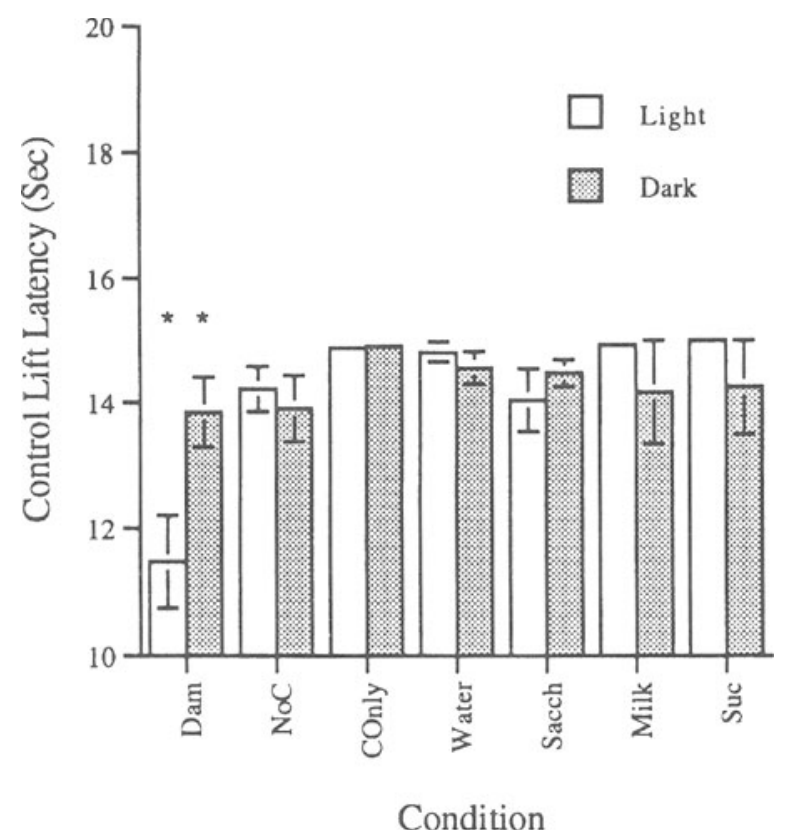

Figure 1. Control lift latencies for activity level, taken with $\mathrm{a}^{\circ} \mathrm{C}$ heating pad, were at or near the cutoff of $15 \mathrm{sec}$ for most groups under light and dark conditions, with the exception of dam control pups, for which they were shorter during the light than during the dark condition $\left({ }^{* *} p<.01\right)$. Dam, dam control; NoC, no-cannula control; COnly, cannula-only control; Water, distilled water; Sacch, $0.15 \%$ saccharin; Milk, half and half; Suc, $9 \%$ sucrose. 


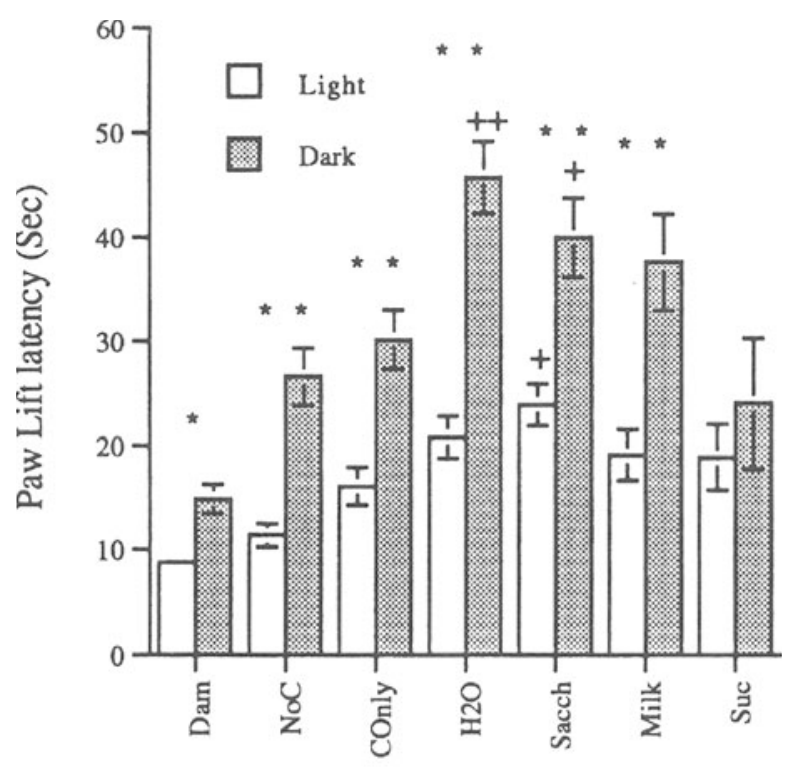

\section{Condition}

Figure 2. Paw lift latencies from a $48.5^{\circ} \mathrm{C}$ surface were longer during the dark phase of the diurnal cycle (dark bars) than during the light (light bars) in all conditions except sucrose $\left({ }^{\star} p<.05\right.$; $\left.\star^{\star} p<.01\right)$; after oral infusion with fuids, paw lift latencies were greater with saccharin during the light and dark, and with water during the dark, than they were for the corresponding cannula-only group $(+p<.05 ;++p<.01)$. Dam, dam control; NoC, no-cannula control; COnly, cannula-only control; H2O, distilled water; Sacch, $0.15 \%$ saccharin; Milk, half and half; Suc, $9 \%$ sucrose.

tencies than the dark-cannula-only control $(p<.01$ for each), and the latencies for the milk group were close to being greater $(p=.066)$. Comparison of paw lift latencies among combined (light and dark) fluid groups indicated that water, saccharin, and milk were all greater than sucrose $(p<.01$ for water and saccharin, $p<.05$ for milk), but did not differ from each other.

\section{DISCUSSION}

\section{Diurnal Cycle}

The present work indicates clearly that a diurnal rhythm in antinociception is present in infant rats. The effect of time of day on antinociception was comparable to the effect reported in adult rats and mice, with minimal effects during the early light phase and strong effects during the dark (Akunne \& Soliman, 1987; Bar-Or \& Brown, 1989). In adults, a role of endogenous opioids (EOs) has been identified in controlling antinociception, as is indicated by the elevation of thresholds by morphine and by the reduction in thresholds by such opiate receptor blockers as naloxone (Fredrickson et al., 1977; Pilcher, Jones, \& Brown, 1982). Whether a similar cycling of EO levels operates in infant rats remains to be demonstrated. Suggestive evidence in favor of this idea is provided by the observation that opioids play a role in regulating hormonal activity in the hypothalamus (Jacobson \& Wilkinson,
1985), and by data gathered in our lab which have shown that pups' paw lick latencies in the dark are reduced by naloxone (Green, 1995; Green \& Chao, 1996).

One mechanism that may have operated in the present experiment to vary the antinociceptive thresholds in the pups is food deprivation, which in adult rats has been reported to produce antinociception (Bodnar, Kelly, Spiaggia, \& Glusman, 1978; McGivern \& Berntson, 1980) and to lead to tolerance to EOs (Davidson, McKenzie, Tujo, \& Bish, 1992). Mother rats tend to feed their pups more during the light phase of the diurnal cycle than during the dark phase (Levin \& Stern, 1975); thus the higher nociceptive thresholds during the dark could have been attributable to food deprivation. To check this possibility, we examined the control paw lift latencies of the pups in the dam control group as a function of whether or not they had been nursing when taken from the dam immediately prior to the paw lift test. In the light condition, 20 of the 28 pups for which a determination was available had been nursing, but there was no difference in mean control lift latencies (nursing, $11.80 \mathrm{sec}, S D=$ 3.47 ; not nursing, $11.75 \mathrm{sec}, S D=4.17$ ). In the dark condition, 15 of 25 pups had been nursing, and again there was no difference between groups in mean control lift latencies (nursing, $13.3 \mathrm{sec}, S D=3.61$; not nursing, $14.7 \mathrm{sec}, S D=0.94$ ). Given the lack of differential latencies as a function of feeding in the dam control group, and given the fact that higher latencies were generally obtained in groups that were infused than in groups that were not, it appears unlikely that the difference in antinociceptive thresholds in the light and dark conditions was attributable to differential feeding experience. Rather, the available data suggest that the difference was attributable to cycling of EOs.

\section{Fluids}

Nociceptive thresholds were elevated by two of the three flavored fluids and by water. The most consistent fluid was saccharin, which yielded antinociception during both light and dark conditions. During the dark, the antinociceptive effect of saccharin was stronger than during the light, milk was effective enough to approach statistical significance, and, surprisingly, water was very effective. Also surprising was the finding that sucrose had no effect at either time of day. The potency of saccharin in producing antinociception in infant rats is consistent with the findings of Kehoe and Sakurai (1991), who found that the effect was reversed by naltrexone. In adult rats, Marks-Kaufman, Kanarek, and Delanty (1988) reported a similar effect on nociception, and the relationship between saccharin and EO activity has been further supported by demonstrations of cross tolerance with morphine (Lieblich, Cohen, Ganchrow, Blass, \& Bergmann, 1983; Lieblich, Yirmiya, \& Liebeskind, 1991). Milk has also been found to produce naltrexone-reversible antinociception in infants (Blass \& Fitzgerald, 1988; Blass, Jackson, \& Smotherman, 1991) and to condition opioid activity in fetal rats (Robinson, Arnold, Spear, \& Smotherman, 1993). 
Water has normally been used as a fluid to control for the physical aspects of infusion of liquids into the mouth, and it was not expected to impart the significant degree of antinociception found in the present study. The effect has proved to be consistent: in four other experiments, observations on a total of 40 pups tested with water in the dark have revealed a mean paw lift latency of about $40 \mathrm{sec}$ as opposed to a mean of about $25 \mathrm{sec}$ in littermate $d a r k$-cannula-only controls. To the human taster, water has a distinctive flavor, albeit one that is typically categorized as neutral. Because the pups' taste experience had been based entirely on mother's milk, exposure to the taste of water may have been sufficient to release EOs. It is possible that the novelty of the water may account for our findings. However, an explanation based on novelty must pass at least two hurdles. First, it is not clear why antinociception was not seen in response to sucrose solution, the taste of which may be at least as novel as that of distilled water. Second, strong analgesic responses were obtained to milk, which presumably has a familiar taste. An alternative hypothesis is that the water effect is attributable to the strain of rats that we used. It is possible that our Wistar pups react differently than the Sprague-Dawley pups used by most other investigators. For example, preliminary data from our lab indicate that adult Wistars may be more reactive to flavors and morphine than SpragueDawleys (Lyon, Aguila, Acevedo, \& Green, 1995).

Our failure to find significant antinociception from sucrose was unexpected, as was the lack of effect of time of day in the sucrose groups. Sucrose has produced calming and antinociception in infant rats (Blass et al., 1987) and infant humans (Miller, Barr, \& Young, 1994; Roane \& Martin, 1990; B. A. Smith, Fillion, \& Blass, 1990). In adult rats, sucrose has been linked to EO-mediated antinociception (Kanarek, White, Biegen, \& Marks-Kaufman, 1991; Lubin, Kest, \& Bodnar, 1991; Schoenbaum, Martin, \& Roane, 1989; Simon \& Dewey, 1981). Nonetheless, it has been reported that the analgesia produced by sucrose in adult rats is weak in comparison with that produced by saccharin (Marks-Kaufman et al., 1988), which is consistent with our findings.

In summary, it appears that nonnutritive fluids produced stronger antinociception than did nutritive fluids. The involvement of EOs has been established by the findings of others, as noted above, and has been supported by our own findings which indicate that antinociception from infusion of milk (Beitner, Werner, Schlundt, \& Green, 1994) or saccharin (Green \& Chao, 1996) can be attenuated by naloxone. Flavor thus appears to be a key factor in activating EOs, and the effectiveness of EOs may actually be reduced by the actions of nutrients (Melchior et al., 1991; Melchior et al., 1994).

\section{Control Groups}

The results of the three control groups indicate that our oral-infusion procedures activated antinociceptive systems. Dam control pups were more active than pups in any other groups, especially during the light condition, as is reflected in the data on both the control lifts (Fig- ure 1) and the test lifts (Figure 2). The test lift data indicate that the increasing amounts of stress entailed in the procedures used for the no-cannula and cannula-only controls led to increasing latencies.

The fact that procedural stress significantly elevated antinociceptive thresholds indicates that care must be taken in interpreting data from oral infusion of fluids. Kehoe and Sakurai (1991) dealt with this problem by habituating pups to procedures and by allowing each pup a minute with an anesthetized dam between infusion and testing. Shide and Blass (1989) kept pups with an anesthetized dam, conducted the infusions in that setting, and included no-cannula and cannula-only controls. In the present study, as in Shide and Blass, the use of the cannulaonly group as a control for fluid infusion allowed comparisons between groups that were roughly equivalent in amount of procedural stress. An improved control procedure might be to connect tubing to the pup's cannula and pump air for the same duration as that during which fluid is infused in the experimental groups. Such a control is currently being examined in our lab (Green \& Chao, 1996). In the present study, we chose to use the cannula-only control group for evaluation of the effects of fluid infusion; for us, use of a dam control for this purpose would have been inappropriate, especially during light conditions, in view of this group's high activity level, which led to a large percentage of pups with rapid responses during the control lifts and presumably also during the test lifts. The present findings indicate the value of assessing the effects of stress engendered in the experimental procedures in determining appropriate control groups.

\section{Fluids and the Diurnal Cycle}

The results of the oral infusions indicate that antinociception in pups was produced by the nonnutritive fluids saccharin and distilled water, tended to be produced by the nutritive fluid milk, and was not produced by the nutritive fluid sucrose. The results of all groups except the sucrose group indicate that antinociception was increased by testing under dark conditions as opposed to light conditions.

If it is assumed that EO activity was responsible for the antinociceptive effects of darkness and fluid infusions, it is possible that the tonic (hours) effects attributable to diurnal cycling and the acute (minutes) effects attributable to infusions could interact, either by directly adding together or in a subtractive fashion as a result of the development of tolerance. An example of an additive effect is that of Fredrickson et al. (1977), who found that morphine antinociception in adult mice was greater during the dark than during the light parts of the diurnal cycle. An example of a tolerance effect has been observed in adult rats: prolonged activation of EOs as a result of chronic saccharin exposure results in cross tolerance for morphine (Gogas, Kirtland, \& Cannon, 1985; Lieblich et al., 1983); the effect can be obtained with saccharin exposure as brief as $3 \mathrm{~h}$ (Fidler, Kalman, Ziemer, \& Green, 1993; Klein \& Green, 1988). Our data indicate an addi- 
tive effect of EOs attributable to diurnal cycling and fluid exposure. The additive effect indicates that tolerance to the EOs activated by fluids is not developed as a result of the prolonged presence of EOs associated with the diurnal cycle. Perhaps the lack of attentuation of fluid effects by darkness indicates that the two factors activate different EOs. The antinociception that varies with the diurnal cycle is attenuated by naloxone, which acts primarily at mu receptors (Fredrickson et al., 1977). With respect to fluids, kappa receptors have been reported to mediate the effects of milk (Smotherman \& Robinson, 1992) and sucrose (Lynch \& Burns, 1990), while saccharin intake has been tied to activity at mu and delta receptors, but not at kappa receptors (Gosnell \& Majchrzak, 1989). These differences in receptor mechanisms may be consistent with the effects of different foods on morphine analgesia (Marks-Kaufman et al., 1988), but they do not make a strong case for differences in mechanisms of antinociception activated by the diurnal cycle and by foods. Perhaps the receptor machinery required for the acquisition of tolerance is not yet developed in the 10-day-old rat, as is indicated by the data of Fanselow and Cramer (1988). If so, combinations of opioid activity that might produce cross tolerance in adults would instead produce additive effects in infants until the mechanisms have matured. The mechanisms of tolerance mature about the time of weaning, when pups would be forced to leave the dam and fend for themselves. Until this time, any events that facilitate EO release would produce calming, aid bonding with the dam, and help conserve energy, all of which are important for infant development.

\section{REFERENCES}

AkunNe, H. C., \& Soliman, K. F. A. (1987). The role of opioid receptors in diabetes and hyperglycemia-induced changes in pain threshold in the rat. Psychopharmacology, 93, 167-172.

Bar-Or, A., \& Brown, G. M. (1989). Pineal involvement in the diurnal rhythm of nociception in the rat. Life Sciences, 44, 1067-1075.

Beitner, R. J., Werner, S. O., Schlundt, C. E., \& Green, K. F. (1994, April). Diurnal cycle and flavor effects on analgesia in infant rats. Poster session presented at the annual meeting of the Western Psychological Association, Kona, HI.

BLASS, E. M. (1992). The ontogeny of motivation: Opioid bases of energy conservation and lasting affective change in rat and human infants. Current Directions in Psychological Science, 1, 116-120.

Blass, E. M., \& FitzGerald, E. (1988). Milk-induced analgesia and comforting in 10-day-old rats: Opioid mediation. Pharmacology, Biochemistry \& Behavior, 29, 9-13.

Blass, E. M., Fitzgerald, E., \& KehOE, P. (1987). Interactions between sucrose, pain and isolation distress. Pharmacology, Biochemistry \& Behavior, 26, 483-489.

Blass, E. M., Jackson, A. M., \& Smotherman, W. P. (1991). Milkinduced, opioid-mediated antinociception in rats at the time of cesarean delivery. Behavioral Neuroscience, 105, 677-686.

Bodnar, R. J., Kelly, D. D., Spiaggia, A., \& Glusman, M. (1978). Biphasic alterations of nociceptive thresholds induced by food deprivation. Physiological Psychology, 6, 391-395.

Davidson, T. L., McKenzie, B. R., Tujo, C. J., \& Bish, C. K. (1992) Development of tolerance to endogenous opiates activated by $24-\mathrm{h}$ food deprivation. Appetite, 19, 1-13.

FANSElOW, M. S., \& CRAMER, C. P. (1988). The ontogeny of opiate tolerance and withdrawal in infant rats. Pharmacology, Biochemistry \& Behavior, 31, 431-438.
Fidler, P., Kalman, B. A., Ziemer, H. E., \& Green, K. F. (1993). Early onset of reduced morphine analgesia by ingestion of sweet solutions. Physiology \& Behavior, 53, 167-171.

Fredrickson, R. C. A., Burgis, V., \& Edwards, J. D. (1977). Hyperalgesia induced by naloxone follows diurnal rhythm in responsivity to painful stimuli. Science, 198, 756-758.

Gogas, K. R., KirTland, D. S., \& CANNON, J. T. (1985). Variations in saccharin intake are related to formalin pain reactivity and the analgesic effects of morphine. Society for Neuroscience Abstracts, 11 , 132.

GosNELl, B., \& MAJChRZAK, M. J. (1989). Centrally administered opioid peptides stimulate saccharin intake in nondeprived rats. Pharmacology, Biochemistry \& Behavior, 33, 805-810.

GREEN, K. F. (1995, November). Flavor-and diurnal-produced analgesia in infant rats: Opioid mediation? Paper presented at the annual meeting of the Psychonomic Society, Los Angeles.

GreEn, K. F., \& ChaO, K. H. (1996). [Effects of nalexone on analgesia induced by saccharin exposure in infant rats]. Unpublished data.

Honma, K., Honma, S., Shirakawa, T., \& Hiroshige, T. (1987). Phase setting of circadian locomotor rhythm of infant rats. Endocrinology, 114, 1791-1796.

JACOBSON, W., \& WILKINSON, M. (1985). Diurnal changes in the opiatergic control of $\mathrm{LH}$ release in prepubertal rats are associated with diurnal variations in hypothalamic but not cortical [3H]-naloxone binding sites. Society for Neuroscience Abstracts, 11,910.

Kanarek, R. B., White, E. S., Biegen, M. T., \& Marks-Kaufman, R (1991). Dietary influences on morphine-induced analgesia in rats Pharamcology, Biochemistry \& Behavior, 38, 681-684.

KaVAliers, M., \& Hirst, M. (1983). Daily rhythms of analgesia in mice: Effects of age and photoperiod. Brain Research, 279, 387-393.

Kehoe, P., \& Sakurai, S. (1991). Preferred tastes and opioidmodulated behaviors in neonatal rats. Developmental Psychobiology, 24, 135-148.

KLEIN, S. P., \& GREEN, K. F. (1988). Tolerance to morphine analgesia from brief exposure to a palatable solution. Brain Research Bulletin, 21, 963-965.

LEVin, R., \& STERn, J. M. (1975). Maternal influences on ontogeny of suckling and feeding rhythms in the rat. Journal of Comparative \& Physiological Psychology, 89, 711-721.

Lieblich, I., Cohen, E., Ganchrow, J. R., Blass, E. M., \& Bergmann, F. (1983). Morphine tolerance in genetically selected rats induced by chronically elevated saccharin intake. Science, 221, 871-873.

Lieblich, I., YiRmiYa, R., \& Liebeskind, J. C. (1991). Intake of and preference for sweet solutions are attenuated in morphinewithdrawn rats. Behavioral Neuroscience, 105, 965-970.

LUbin, E., KEST, B., BODNAR, R. J. (1991). Differential actions of central alloxan upon opioid and nonopioid antinociception in rats: $A$ further examination. Brain Research Bulletin, 27, 35-39.

LyNCH, W. C., \& BurNs, G. (1990). Opioid effects on intake of sweet solutions depend both on prior drug experience and on prior ingestive experience. Appetite, 15, 23-32.

Lyon, D. C., Aguila, J. C., Acevedo, M., \& Green, K. F. (1995, March). Rat strain differences in reduced morphine analgesia through flavor experience ( $R M A F E$ ) and measures of taste reactivity. Poster presented at the annual meeting of the Western Psychological Association, Los Angeles.

Marks-Kaufman, R., Kanarek, R. B., \& Delanty, S. N. (1988). Sweet-tasting solutions modify the analgesic properties of morphine in rats. FASEB Journal, $2, \mathrm{~A} 1567$.

McGivern, R. F., \& BERNTSON, G. G. (1980). Mediation of diurnal fluctuations in pain sensitivity in the rat by food intake patterns: Reversal by naloxone. Science, 210, 210-211.

Melchior, J. C., Fantino, M., Colas-Linhart, N., Rigaud, D., Petiet, A., Laforest, M. D., Fumeron, F., \& Apfelbaum, M. (1991). Lack of plasmatic beta-endorphin response to a gastronomic meal in healthy humans. Physiology \& Behavior, 49, 1217-1221.

Melchior, J. C., Rigaud, D., Chatvialle, J.-A., Colas-Linhart, N., Laforest, M. D., Petiet, A., Comoy, E., \& Apfelbaum, M. (1994). Palatability of a meal influences release of beta-endorphin, and of potential regulators of food intake in healthy human subjects. $A p$ petite, 22, 233-244. 
Miller, A., Barr, R. G., \& Young, S. N. (1994). The cold pressor test in children: Methodological aspects and the analgesic effect of intraoral sucrose. Pain, 56, 175-183.

Nusselein, B., \& SCHMIDT, I. (1990). Early development and postnatal zeitgebers of circadian temperature rhythm in rat pups. Neuroendocrinology, 52(S1), 105.

Phifer, C. B., \& Hall, W. G. (1987). Development of ingestive behavior. In F. M. Toates \& N. E. Rowland (Eds.), Feeding and drinking (pp. 189-230). New York: Elsevier.

Pilcher, C. W. T., Jones, S. M., \& Browne, J. (1982). Rhythmic nature of naloxone-induced aversions and nociception in rats. Life Sciences, 31, 1249-1252.

RoAne, D. S., \& MarTin, R. J. (1990). Continuous sucrose feeding decreases pain threshold and increases morphine potency. Pharmacology, Biochemistry \& Behavior, 35, 225-229.

Robinson, S. R., Arnold, H. M., Spear, N. E., \& Smotherman, W. P. (1993). Experience with milk and an artificial nipple promotes conditioned opioid activity in the rat fetus. Developmental Psychobiology, 26, 375-387.

Schoenbaum, G. M., Martin, R. J., \& Roane, D. S. (1989). Relationships between sustained sucrose-feeding and opioid tolerance and withdrawal. Pharmacology, Biochemistry \& Behavior, 34, $911-914$.

SHIDE, D. J., \& BLASs, E. M. (1989). Opioidlike effects of intraoral infusions of corn oil and polycose on stress reactions in 10-day-old rats. Behavioral Neuroscience, 103, 1168-1175.

Simon, G. S., \& DewEY, W. L. (1981). Narcotics and diabetes: I. The effects of streptozotocin-induced diabetes on the antinociceptive potency of morphine. Journal of Pharmacology \& Experimental Therapeutics, 218, 318-323.

SMith, B. A., Fillion, T. J., \& Blass, E. M. (1990). Orally mediated sources of calming in 1- to 3-day-old human infants. Developmental Psychology, 26, 731-737.

SMith, G. K., \& ANDERSON, V. (1977). Effects of maternal isolation on the development of activity rhythms in infant rats. Physiology \& Behavior, 18, 775-779.

Smotherman, W. P., \& Robinson, S. R. (1992). Kappa opioid mediation of fetal responses to milk. Behavioral Neuroscience, 106, 396407.

Sugishita, M., Takashima, M., Takeuchi, Y., Kato, Y., Yamauchi, T., \& Takahashi, K. (1993). Periodic mother deprivation reversed the phase of serotonin $N$-acetyltransferase activity rhythm of the pineal gland in rat pups. Pharmacology, Biochemistry \& Behavior, 46, 609-615.

Takahashi, K., Hayafuji, C., \& Murakami, N. (1982). Foster mother rat entrains circadian adrenocortical rhythm in blinded pups. American Journal of Physiology, 325, E443-E449.

Wirz-Justice, A. (1987). Circadian rhythms in mammalian neurotransmitter receptors. Progress in Neurobiology, 29, 219-259.

(Manuscript received January 22, 1996; revision accepted for publication July 3, 1996.) 